\title{
O paradoxo do direito de autor na legislação brasileira
}

\section{La paradoja de los derechos de autor en la legislación brasileña}

\author{
The paradox of copyright on Brazilian law
}

Eduardo José dos S. de Ferreira Gomes ${ }^{1}$

\begin{abstract}
Resumo:
Palavras chave:

O presente artigo tem como proposta refletir sobre o sistema de propriedade intelectual e de direitos autorais, o direito de autor nas músicas e algumas teorias da ciência cultural, sugerindo um

Direitos Autorais

Propriedade Intelectual paradoxo: o direito de autor é um monopólio estatal que garante a remuneração autoral em contrapartida da publicação da obra,

Acesso à Cultura efetivando o acesso à cultura; entretanto, algumas práticas da indústria fonográfica brasileira promovem a desvirtuação do direito de autor, que o distancia de sua ratio legis.
\end{abstract}




\section{Resumen:}

Este artículo tiene como objetivo reflexionar sobre el sistema de propiedad intelectual y derechos de autor, los derechos de autor sobre las canciones y algunas teorías de la ciencia cultural, lo que sugiere una paradoja: el derecho de autor es un monopolio estatal que asegura cuota de copyright en la contrapartida de la publicación de la obra, efectuando el acceso a la cultura; sin embargo, algunas prácticas de la industria musical brasileña promueven la distorsión del derecho de autor, que lo aleja de su ratio legis.
Palabras clave:

Derecho de Autor

Propiedad Intelectual

Acceso a la Cultura

\section{Keywords:}

Copyright

Intellectual Property

Access to culture

\section{Abstract:}

This article has the proposal of reflecting on the system of intellectual property rights and copyright, the copyright in the music and some theories of science, suggesting a cultural paradox: copyright is a state monopoly that guarantees copyright remuneration in return for the publication of the work, effecting access to culture; however, some Brazilian phonographic industry practices promote distortion of copyright, to the distance of their ratio legis. 


\section{O paradoxo do direito de autor na legislação brasileira}

A Propriedade Intelectual é um ramo do Direito que engloba a Propriedade Industrial, os Direitos Autorais e Conexos, e outros direitos sobre bens imateriais. É o conjunto de normas de valores patrimoniais, ou seja, não naturais, que, por consequência, protege as criações do intelecto, mas que, antes disto, nasce para premiar o espírito humano produti$v^{2}{ }^{2}$. É um monopólio estatal que garante a remuneração autoral (inclusive estimulando novas criações) em contrapartida da publicação da obra.

Há, na doutrina, diversas definições de Propriedade Intelectual, mas aqui será adotada a da Organização Mundial da Propriedade Intelectual (OMPI) ${ }^{3}$. De acordo com a OMPI, Propriedade Intelectual abrange a soma dos direitos relativos às obras literárias, artísticas e científicas, às interpretações dos artistas intérpretes e às execuções dos artistas executantes, aos fonogramas e às emissões de radiodifusão, às invenções em todos os domínios da atividade humana, às descobertas científicas, aos desenhos e modelos industriais, às marcas industriais, comerciais e de serviço, bem como às firmas comerciais e denominações comerciais, à proteção contra a concorrência desleal e todos os outros direitos inerentes à atividade intelectual nos domínios industrial, científico e artístico. Pelo caráter muito internacionalizado no capítulo do Direito, a Propriedade Intelectual é um importante instrumento de promoção das comunicações entre culturas, de difusão do conhecimento e de desenvolvimento tecnológico; fatores determinantes para o crescimento econômico do país.

Com o Decreto Presidencial de 21de agosto de 2001, foi criado, no âm- bito da Câmara de Comércio Exterior CAMEX (órgão de Conselho do Governo que assessora diretamente a Presidência da República), o Grupo Interministerial de Propriedade Intelectual - GIPI. Apesar de ter sua criação datada do ano de 2001 , as origens do grupo são de meados da década de 1980, com uma turma formada para assessorar o governo na Rodada do Uruguai, conforme veremos adiante, resultando no Acordo TRIPs (Trade RelatedAspectsofIntellectualPropertyRights) ou ADPIC (Acordo Sobre Aspectos dos Direitos de Propriedade Intelectual Relacionados ao Comércio).

A atribuição do GIPI, conforme art. $1^{\circ}$ do decreto que o instituiu, é propor a ação governamental no sentido de conciliar as políticas interna e externa visando o comércio exterior de bens e serviços relativos à Propriedade Intelectual.

Art. $1^{\circ}$ - Fica criado, no âmbito da CAMEX - Câmara de Comércio Exterior, o Grupo Interministerial de Propriedade Intelectual - GIPI, com a atribuição de propor a ação governamental no sentido de conciliar as políticas interna e externa visando o comércio exterior de bens e serviços relativos a propriedade intelectual e, especialmente:

I - aportar subsídios para a definição de diretrizes da política de propriedade intelectual;

II - propor o planejamento da ação coordenada dos órgãos responsáveis pela implementação dessa política;

III - manifestar-se previamente sobre as normas e a legislação de propriedade intelectual e temas correlatos;

IV - indicar os parâmetros técnicos para as negociações bilaterais e multilaterais em matéria de propriedade intelectual;

V - aportar subsídios em matéria de propriedade intelectual para a formulação e implementação de outras políticas governamentais; 
VI - promover a coordenação interministerial nos assuntos que serão tratados pelo GIPI;

VII - realizar consultas junto ao setor privado em matéria de propriedade intelectual;

VIII - instruir e reportar matérias relativas à propriedade intelectual.

A relação dos resultados do grupo é bem extensa, como por exemplo, a adequação da legislação nacional aos acordos internacionais, como a Lei de Direitos Autorais (Lei $n .^{\circ}$ 9.610/98), a Lei da Propriedade Industrial (Lei n. ${ }^{\circ}$ 9.279/96), a Lei de Cultivares (Lei n. ${ }^{\circ}$ 9.456/97), a Lei de Programas de Computador (Lei n. ${ }^{\circ}$ 9.609/98), dentre outros.

São diversas as formas de Propriedade Intelectual e cada espécie tem a sua determinada proteção. A Lei da Propriedade Industrial (Lei n. ${ }^{\circ}$ 9.279/96), em seu art. $2^{\circ}$, traz o rol de alguns objetos da Propriedade Industrial, por sua vez, espécie de Propriedade Intelectual, tais como: Patentes de Invenção, Patentes de Modelo de Utilidade, Desenhos Industriais, Marcas, bem como a repressão à concorrência desleal e às Indicações Geográficas. Há outras espécies de Propriedade Intelectual protegidas pela legislação. São exemplos: direitos autorais (Lei 9.610/98), programa de computador (Lei 9.609/98), o nome de empresa ou nome comercial (de responsabilidade das Juntas Comerciais e dos Registros Civis de Pessoas Jurídicas), topografia de semicondutores (Lei 11.484/07), cultivares (Lei $9.456 / 97$ ) e os dados confidenciais apresentados às autoridades para autorização de comercialização de agrotóxicos e outros produtos (Lei 10.603/02). Entretanto, o esperado é que tenhamos, além desses exemplos, cada vez mais objetos de Propriedade Intelectual.

A Propriedade Intelectual é um sistema internacional ${ }^{4}$ com acordos que im- põem direitos ${ }^{5}$, pois há países que são mais propensos à produção de tecnologia (e isso ocorre por diversos fatores, como acúmulo de capital e concentração financeira, entre outros), e outros países à produção de alimentos, matérias-primas e outras atividades. De modo que, pelas diferenças de produção entre os países há a necessidade de exploração de mercados diferentes de forma a incluir a área internacional gerando benefícios para todos.

Quando um país concede um monopólio de exploração, por exemplo, a um titular de um invento, fica em desvantagem em relação a outro que não tenha concedido, pois no país da concessão os preços não sofrerão concorrência, sendo, portanto, preços monopolistas. Todavia, quando se internacionaliza a exploração os preços e a qualidade serão os melhores possíveis, pois haverá racionalização na produção de bens que serão vendidos, com exclusividade, em todo o mundo.

Direitos Autorais é apenas uma das espécies do gênero Propriedade Intelectual. Entretanto, a única, conforme a Convenção da União de Berna (CUB), em que a proteção nasce com a obrae não necessita de registro prévio."O registro da obra tutelada pelo Direito Autoral é facultativo e meramente declaratório"(WACHOWICZ, 2012, p. 4).

De acordo com a Constituição da República Federativa do Brasil (Brasil, 2013), art. $5^{\circ}, \mathrm{XXVII}$, "aos autores pertence o direito exclusivo de utilização, publicação ou reprodução de suas obras, transmissível aos herdeiros pelo tempo que a lei fixar".Como explica Ascensão (2010), esse direito exclusivo, do ponto de vista patrimonial, significa monopólioe é um monopólio de utilização, se definindo como uma proteção muito mais direcionada ao investimento do que à criação intelectual. 
Com o surgimento e crescimento da internet, que possibilitou o compartilhamento e difusão de obras protegidas pela Lei de Direitos Autorais, o mercado fonográfico obteve um decréscimo nas altíssimas margens de lucro. Tal acontecimento gerou um conflito de direitos. Por um lado, havia os titulares de direitos autorais alegandoviolações em seus direitos, por outro, usuários de programas de compartilhamento e público em geral que ainda utilizam de mecanismos para obtenção de obras protegidas e que alegam o direito ao acesso às obras.

A internet revolucionou a produção musical fazendo com que o artista iniciante tivesse, ao menos, um canal de visibilidade antes impossibilitado pelo domínio do mercado fonográfico. No século XIV, conforme Piccino (2000), as editoras contratavam compositores e autores. Com a invenção do gramofone, no século XIX, surgiram as gravadoras e estas passaram a contratar artistas para gravações. Entretanto, os artistas já estavam vinculados às editoras, o que fez com que elas funcionassem como agentes intermediários.

As gravadoras ficaram responsáveis pelo processo de produção, distribuição e promoção dos fonogramas, enquanto as editoras se responsabilizaram pelos direitos de reprodução do repertório a ser gravado. Em outras palavras, os compositores cederam às editoras e gravadoras os seus direitos autorais patrimoniais em troca da promoção das composições.

O negócio do mercado fonográfico estava baseado no controle do suporte físico, como por exemplo, os cilindros, o 78 r.p.m. (rotações por minuto), o 45 r.p.m, o LP (Long play), a fita magnética e o CD (CompactDisc) ficando, assim, financeiramente prejudicado.O 78 r.p.m., não tinha capa personalizada e, em geral, os discos traziam publicidade da gravadora. Em 1964, o 78 r.p.m.saiu do mercado e surgiu o 45 r.p.m. e o compacto 6' para a gravação de músicas de divulgação. O LP 12' obteve um grande impacto no mercado e o artista se tornou mais importante do que o disco em si, passando a ter capa conceitual. No Brasil, em 1958, Elizeth Cardoso foi uma das primeiras artistas que utilizou LP.

A partir dos anos 1980, a "onipresença" das gravadoras multinacionais abrangia até as produções independentes regionais. Pequenos selos associavam-se a empresas maiores para viabilizar a logística de distribuição de produtos ao varejo e a arrecadação do valor das vendas - relação muitas vezes marcada por conflitos e insatisfações. Mas, na década seguinte, a indústria fonográfica não se ocupou mais detidamente com uma reestruturação que incluísse em seus negócios a crescente circulação mundial da música via internet, com a popularização do formato MP32 e do acesso à navegação em banda larga, o que fomentou a prática do compartilhamento de arquivos musicais entre ouvintes, mediante uploads e downloads ou escuta em streaming de arquivos musicais (LIMA, 2013, p. 10).

Com a mercantilização da cultura, o direito autoral foi utilizado pela indústria cultural para proteger os investimentos, não apenas para a proteção, propriamente dita, da criatividade estética e científica. Bandeira (2005) entende que;

a indústria fonográfica possui uma relação direta com a propriedade intelectual e direitos autorais, dependendo destes elementos para a manutenção de suas atividades econômicas. Veremos que, durante a década de 1990, a indústria fonográfica vai deslocar seu objeto de receita das vendas de discos para a cobrança de royalties e direitos autorais. Isto irá legar às gravadoras 
o espírito de combate à evolução dos sistemas de compartilhamento de arquivos musicais pela Internet uma vez que, segundo as mesmas, este fenômeno fere os direitos de autoria e propriedade intelectual, atingindo diretamente as receitas de artistas e de companhias do disco (BANDEIRA, 2005, p. 7).

Especificamente, o mercado fonográfico, dentro da indústria cultural, se tornou um grande negócio que dominava desde a concepção da música. Na prática, este mercado sacraliza os direitos autorais como absolutos, plenos, naturais e ilimitados criando, desta forma, um mecanismo que faz com que os autores dependam dos agentes de mercado e, por fim, impõem a cessão permanente dos direitos autorais.

Nesta lógica, os direitos autorais são absolutos, mas os titulares, na maioria dos casos, não são mais os autores e artistas e, sim, os empresários investidores. Ou seja, o direito absoluto, pleno, natural e ilimitado era defendido para benefício próprio. Conforme Bandeira (2005), a indústria fonográfica tem vocações mercadológicas:

Se, por um lado, a história da música popular possui um lastro social, cultural e antropológico, onde há uma infinidade de aspectos estruturantes de sua configuração (grupos sociais, questões de identidade, gênero etc.), por outro, há uma história concomitante (e convergente) da tecnologia musical (instrumentos musicais, discos, fitas, técnicas de gravação etc.) que também se apresenta enquanto elemento estruturante desta evolução. Veremos, então, que o êxito da música popular está diretamente associado à junção entre o avanço dos sistemas de gravação sonora e a exploração de um determinado estilo musical. Será importante delimitar, aqui, o viés econômico que orienta a indústria fonográfica, pois, desde o seu nascedouro, podemos notar suas vocações mercadológica e multinacional (BANDEIRA, 2005, p. 5).

Em verdade, a corrente de pensamento que defende os Direitos Intelectuais como plenos, absolutos, exclusivos e naturais usam deste discurso com o intuito de legitimar o excesso da proteção para que a exploração econômica seja máxima.

Neste cenário de conflito entre direitos privados (direitos autorais) e direitos coletivos (acesso às culturas) o desafio é encontrar os limites de cada um destes direitos. Para tanto, é necessária uma breve reflexão sobre alguns estudos acerca da teoria da cultura.

De acordo com Couche (2002), nas ciências sociais ${ }^{6}$, uma das noções modernas de cultura muito aceita é aquela que remete aos modos de vida e de pensamento, embora tenha suscitado contestações na busca da justa definição da palavra, uma vez que as lutas de definição do termo são "lutas sociais, e o sentido a ser dado às palavras revelam questões sociais fundamentais" (COUCHE, 2002, 20). Segundo o autor, pode-se considerar o século XVIII como o período de formação do sentido moderno da palavra passando da cultura como estado (por exemplo, cultura de feijão) à cultura como ação (cultivar a terra), ou ainda, da cultura da terra à cultura do espírito (em sentido figurado).

O termo 'cultura' no sentido figurado começa a se impor no século XVIII. Ele faz sua entrada com este sentido no Dicionário da Academia Francesa (edição de 1718) e é então quase sempre seguido de um complemento: fala-se da 'cultura das artes', da 'cultura das letras', da 'cultura das ciên- 
cias', como se fosse preciso que a coisa cultivada estivesse explicitada. (Couche, 2002, p. 20).

A invenção do conceito científico de Cultura (em sentido figurado), conforme explica Couche (2002), percorre, a priori, diversas correntes e não sugere um entendimento sobre o uso do conceito no singular - a Cultura -, numa acepção universalista, ou no plural - as Culturas -, em uma acepção particularista. O autor analisa a primeira definição etnológica de cultura proposta por Edward Tylor, atribuindo a ela a intenção de ser apenas descritiva e objetiva, não normativa, rompendo com as definições individualistas, já que, para Tylor, a cultura é a expressão da totalidade da vida social do homem.

Cultura e civilização, tomadas em seu sentido etnológico mais vasto, são um conjunto complexo que inclui o conhecimento, as crenças, a arte, a moral, o direito, os costumes e as outras capacidades ou hábitos adquiridos pelo homem enquanto membro da sociedade. (COUCHE, 2002, p. 35).

Ele analisou, ainda, os estudos de Franz Boas, que considerava cada cultura representativa de uma totalidade singular, a partir do qual "um costume particular só pode ser explicado se relacionado ao seu contexto cultural".

Cada cultura é dotada de um 'estilo' particular que se exprime através da língua, das crenças, dos costumes, também da arte, mas não apenas desta maneira. Este estilo, este 'espírito' próprio a cada cultura influi sobre o comportamento dos indivíduos (COUCHE, 2002, p. 45) (Grifo nosso).

Couche (2002) explora também a perspectiva estrutural da cultura proposta por Claude Lévi-Straussinfluenciado pelos antropólogos culturais americanos, principalmente, em quatro ideias fundamentais para sua obra: a) a ideia que as diferenças culturais são definidas por certo modelo; b) que os tipos de culturas possíveis existem em número limitado; c) que o estudo das sociedades "primitivas" é o melhor método para determinar as combinações possíveis entre os elementos culturais; d) que estas combinações podem ser estudadas em si mesmas independente dos indivíduos que pertencem ao grupo para quem estas combinações permanecem inconscientes. Porém, se diferencia, conforme Couche (2002), ao procurar ultrapassar a abordagem particularista das culturas entendendo que "as culturas particulares não podem ser compreendidas sem referência à Cultura, 'este capital comum' da humanidade do qual elas se alimentam para elaborar seus modelos específicos".

Toda cultura pode ser considerada como um conjunto de sistemas simbólicos. No primeiro plano destes sistemas colocam-se a linguagem, as regras matrimoniais, as relações econômicas, a arte, a ciência, a religião. Todos estes sistemas buscam exprimir certos aspectos da realidade física e da realidade social, e mais ainda, as relações que estes dois tipos de realidade estabelecem entre si e que os próprios sistemas simbólicos estabelecem uns com os outros. (COUCHE, 2002, p. 95).

Conforme proposto por Lévi-Strauss existe um "capital comum" humano, ou seja, elementos culturais idênticos e invariantes de uma cultura a outra que se relacionam com as estruturas inconscientes do espírito humano. A diversidade cultural aparente é o fruto das interpretações dos povos em seus diferentes sistemas organizacionais da vida. A arte, por exemplo, a música de um determinado povo, é um sistema simbólico que compõe uma específica cul- 
tura, que, de acordo com Lévi-Strauss, exprime certos aspectos da realidade física e social, além das relações com os outros sistemas simbólicos desse grupo. Logo, este bem cultural foi gerado graças a um "capital comum" somado com expressões de realidades coletivas. Então, como é possível que este bem seja tratado como uma propriedade privada oponível erga omnes irrestrita, como propõe a corrente absolutista do sistema de direitos autorais?

Por outro lado, Couche (2002) também analisa o trabalho de Roger Bastide sobre aculturação ${ }^{7}$, no qual se opõe à Lévi-Strauss em sua noção de estrutura, que considera estática demais. De acordo com Couche (2002), toda cultura é um processo permanente de construção, desconstrução e reconstrução, sugerindo, assim, a substituição do termo "cultura" por "culturação" (já contido em aculturação) com o intuito de destacar esta dimensão dinâmica da cultura.

Por esta razão, como mostrou Bastide, o estudo da fase de desconstrução é tão importante do ponto de vista científico quanto a fase de reconstrução, pois é igualmente rica em ensinamentos. Ela revela que a deculturação não é necessariamente um fenômeno negativo que resulta na decomposição da cultura. Se por um lado, a deculturação pode ser o efeito do encontro das culturas, ela pode também agir, por outro lado, como causa de reconstrução cultural. Bastide se apoia no caso exemplar (porque extremo) das culturas afro-americanas: apesar ou talvez por causa dos séculos de escravidão, ou seja, de desconstrução social e cultural quase absoluta, os Negros das Américas criaram culturas originais e dinâmicas. (COUCHE, 2002, p. 137).

Em sua teoria estruturalista, conforme demonstra Couche (2002), Lévi-
-Strauss entende que os fenômenos de deculturação podem levar à decadência cultural como se fosse uma doença. Ao invés de estrutura Bastide propõe "estruturação", "desestruturação" e "reestruturação" entendendo que, nem em todos os casos, a deculturação domina de forma a impedir qualquer reestruturação cultural. Os estudos sobre os fatos da aculturação, segundo o autor, levaram a um reexame do conceito de cultura passando a ser compreendida como um conjunto dinâmico e mais ou menos homogêneo. Assim, os elementos que compõem uma cultura (arte, religião, língua), por terem fontes diversas no espaço e no tempo, não são integrados uns aos outros, logo, nenhuma cultura existe em "estado puro". Não existe uma "cultura pura" nem uma "cultura mestiça", mas, devido aos contatos culturais, todas, em diferentes graus, são "culturas mistas".

Nos estudos das diferenças culturais que opõem os grupos sociais, Pierre Bourdieu, conforme explica Couche (2002), geralmente utiliza o termo cultura em um sentido mais restrito, como aquele que remete às obras culturais, aos produtos simbólicos ligados ao domínio das artes e das letras, em uma perspectiva de estudos dos mecanismos sociais de criação artística. Quando ele trata de cultura no sentido mais amplorecorre a outro conceito; "habitus", sistemas de disposições ou estruturas estruturantes, que caracterizam uma classe ou um grupo social em relação aos outros. Para Bourdieu, habitus funciona como a materialização da memória coletiva reproduzindo ações para os sucessores.

A música é um bem cultural que reflete os saberes, valores, crenças, expectativas, normas, cria identidades e passa a fazer parte da vida das pessoas. Existe, nas músicas, por sua própria natureza, um viés público que deve estar em equilíbrio com a exploração econômica. Entretanto, 
a distribuição de obras está nas mãos de poucas empresas. A indústria cultural decide o que circula e o que se produz; são os donos da vitrine e, por fim, comunicam a existência e o valor da obra. Neste diapasão, o sistema jurídico autoral brasileiro protege muito mais o investimento da indústria cultural do que, de fato, a obra.

Consumir música online é indício de valorização da música, independentemente da ocorrência de remuneração ou não no ato do consumo. Ao que parece, com base nos exemplos acima, os adeptos do compartilhamento de arquivos podem estar dispostos e até acham justo remunerar os produtores da música, embora não encontrem meios para tal e/ou não adiram aos esquemas vigentes de venda de música online.

Afinal, é preciso considerar que as leis as quais regulam o direito autoral ou o direito de cópia (copyright) têm a anuência da sociedade em seus pressupostos básicos que são o intuito de fomentar a criatividade, remunerando o criador para que ele continue produzindo, bem como estimulando que outras pessoas passem a criar. Também têm respaldo social as ideias de que o produtor - seja ele, no caso da música, compositor, instrumentista, ou técnico -, ao criar, mobiliza um repertório de referências acumuladas e advindas de várias fontes de formação e informação cultural, sendo o livre acesso aos bens culturais um estímulo que retroalimenta a criatividade na medida em que igualmente estimula novas criações. (LIMA, 2013, p. 140)

Conforme Coelho (2012), os princípios das indústrias culturais são os mesmos da produção econômica geral em que se utilizam máquinas, ritmo humano de trabalho submetido ao ritmo da máquina e divisão do trabalho. Entretanto, a matéria prima é a cultura. Nesta lógica, a cultura deixa de ser vista como instrumento da livre expressão e do conhecimento para ser mercadoria com cotação individualizável e quantificável.

Os conglomerados da Indústria Cultural que, muitas vezes se concentram nos EUA, exercem também influências nas legislações específicas de outros países, sobretudo, naquelas que regulamentam a proteção e circulação das obras culturais, como a música, literatura, audiovisual, entre outros. No Brasil, a Lei de Direitos Autorais (LDA) - Lei 9.610/1998 é excessivamente restritiva e tem caráter claramente protetivo à exploração econômica da obra. Os bens culturais são tratados como propriedade privada.

$\mathrm{Na}$ maioria dos casos, os autores das criações do espírito querem que suas obras sejam publicadas. A circulação da obra, em regra, só é possível ser feita pelo autor, mas a LDA, a partir do art. 49, prevê mecanismos de autorização para que a obra chegue ao público. São exemplos: o licenciamento, a concessão, a cessão, dentre outros meios legais.

Caracteriza-se a cessão pela transferência da titularidade da obra intelectual, com exclusividade para o(s) cessionário(s). Já a licença é uma autorização dada pelo autor para que um terceiro se valha da obra, com exclusividade ou não, nos termos da autorização concedida. Os seja, a cessão assemelha-se a uma compra e venda (se onerosa) ou a uma doação (se gratuita), e a licença, a uma locação (se onerosa) ou a um comodato (se gratuita). (PARANAGUÁ ; BRANCO, 2009, p. 94).

Os autores precisam de alguns intermediários para a publicação de suas obras, muito embora, com o avanço da tecnologia, seja possível que muitos optem por fazer todo o processo sozinhos. 
Assim, um músico-autor, quase sempre, precisa de alguém que fixe o fonograma e faça cópias de seus CDs, além de celebrar contratos de direitos autorais de suas obras.

Como a prática do mercado de bens culturais, sobretudo, o produto fonográfico, é a realização de cessões permanentes (ou temporárias intituladas de contrato de edição) do autor para o empresário, leis excessivamente protetivas garantem, em verdade, o direito do capital em desfavor ao verdadeiro autor, resultando na blindagem da obra e na perda de domínio do criador. Surge assim o paradoxo: o direito de autor, que pretende proteger as criações do intelectoe premiar o espírito humano produtivo com o intuito de estimular novas criações e fazer a obra circular, traz, no texto da lei brasileira de direitos autorais, a possibilidade de bloqueio da criação e a desproteção do autor.

Desta forma, faz-se necessário uma reforma na legislação brasileira objetivando o aumento da produção criativa, aumento da remuneração do autor, aumento da disponibilidade da obra e consequentemente o aumento da circulação e do acesso, equilíbrio da indústria cultural e a busca de novas formas de negócio, que não a exploração substitutiva autoral via contratos de cessão e licença disfarçados de edição.

\section{Bibliografia}

ARAUJO, Luiz Alberto David ; NUNES JUNIOR, Vidal Serrano. Curso de direito constitucional. 11.ed. São Paulo: Saraiva, 2007.

ASCENSÃO, José de Oliveira. Direito Autoral. Rio de Janeiro: Renovar, 1997.

BANDEIRA, M. G. A economia da música online: propriedade e compartilhamento da informação na sociedade contemporânea. Disponível em http://www.rp-bahia.com.br/biblioteca/pdf/Messias Bandeira.pdfAcesso em 19/12/2013.

BARBOSA, Denis Borges. Tratado da Propriedade Intelectual. Vol. I. Rio de Janeiro: Lúmen Júris, 2010.

BARBOSA, Pedro Marcos Nunes. A usucapião nos privilégios de invenção: a apropriabilidade originária pelo uso reiterado. Dissertação de mestrado em Direito. Rio de Janeiro: Universidade do Estado do Rio de Janeiro, 2011.

BITTAR, Carlos Alberto. O Direito de Autor nos Meios Modernos de Comunicação. Revista dos Tribunais. São Paulo, 1989.

BRASIL. Grupo Interministerial de Propriedade Intelectual (GIPI). Disponível em http:// www.desenvolvimento.gov.br/ arquivos/dwn 1253887906.pdf, Acesso em 21/10/2012.

BRASIL. Ministério da Cultura. Consulta pública para modernização da lei de direito autoral. Disponível em: <http://www.cultura. gov.br/ consultadireitoautoral/> Acesso em $30 / 03 / 11$.

Direitos Autorais, Acesso à Cultura e Novas Tecnologias: Desafios em Evolução à Diversidade Cultural. Rio de Janeiro, 2006.

Direito autoral. Coleção cadernos de políticas culturais; v. 1. Brasília: Ministério da Cultura, 2006.

CERQUEIRA, João da Gama. Tratado da Propriedade Industrial. Vol. II, $2^{a}$. ed. São Paulo: Editora Revista dos Tribunais, 1982.

CHAUÍ, Marilena. Cidadania cultural: o direito à cultura. São Paulo: Editora Fundação Perseu Abramo, 2006.

COELHO, Teixeira. Dicionário crítico de política cultural: cultura e imaginário. 2.ed. São Paulo: lluminuras, 2012.

COUCHE, Denys. A noção de cultura nas ciências sociais. Tradução: Viviane Ribeiro. 2.ed. Bauru: EDUSC, 2002.

CUNHA FILHO, Francisco Humberto. Direitos Culturais como Direitos Fundamentais no Or- 
denamento Jurídico Brasileiro. Brasília: Brasília Jurídica, 2000.

FURLANETTO, Beatriz. Múltiplas Identidades na Pós-Modernidade - Uma Polifonia em Construção. In: Anais do I/ Simpósio Acadêmico de Violão da Escola de Música e Belas Artes do Paraná. Curitiba: Embap, 2008. p. 236-247.

GAMA, Guilherme Calmon Nogueira da. Propriedade Intelectual: questões polêmicas. Revista da Escola da magistratura regional Federal, Tribunal Regional Federal da $2^{\mathrm{a}}$ região. Edição especial de propriedade Intelectual. Rio de Janeiro, 2011.

GIL, Gilberto. Uma nova política cultural para o Brasil. Revista Rio de Janeiro, n.15, jan.-abr. 2005.

LESSIG, Lawrence. Cultura Livre. Como a mídia usa a tecnologia e a lei para barrar a criação cultural e controlar a criatividade. Disponível em http://baixa cultura.org/ biblioteca/3-livros/3-2-cultura-livre-lawrence-lessig/ Acesso em 15/03/2014.

LIMA, Luiz Costa. Introdução, comentários e seleção de Luiz Costa Lima. In: MOLES et al. Teoria da Cultura de massa. São Paulo: Paz e Terra, 2011.

LIMA, Tatiana Rodrigues. O balanço do bit: mediações da música na era digital. Tese de doutorado. 2013.

PARANAGUÁ, Pedro; BRANCO, Sergio. Direitos autorais. Rio de Janeiro: FGV, 2009.

PEREIRA, Wesley Robert. Histórico da $O M C$ : construção e evolução do sistema multilateral de comércio. Disponível em: $<$ http://www.pucminas.br/imagedb/conjuntura/CES_ARQ_DESCR20050927090630.pdf ?PHPSESSID=1a6f75b339c894845fd56f84 eb74ede8> Acesso em 08/03/14.

PICCINO, Evaldo. Um breve histórico dos suportes sonoros analógicos. Surgimento, evolução e os principais elementos de impacto tecnológico. Disponível em http://www.sonora.iar. unicamp.br/sonora1/artigos_pdf/02Suportes Analogicos.pdf Acesso em 19/05/2014.

RUBIM, Antonio Albino Canelas. Políticas Culturais no Brasil: Tristes tradi- ções, enormes desafios. Salvador: EdUFBA, 2007.

SILVA, Tomaz Tadeu. A Produção Social da Identidade e da Diferença. In: SILVA, Tomaz Tadeu (Org.). Identidade e diferença - a perspectiva dos estudos culturais. Petrópolis/RJ: Vozes, 2000.

SOUZA. Allan Rocha de. A função social dos direitos autorais. Campos/RJ: Editora da Faculdade de Direito de Campos, 2006.

TORRI, Veronica. Gestão Coletiva de Direitos Autorais e a Defesa da Concorrência. Rio de Janeiro: Lúmen Juris, 2011.

WACHOWICZ, Marcos. Direito Autoral. Disponível em http://www.direito autoral.ufsc.br/ gedai/download/1/ Acesso em 13/11/12.

\footnotetext{
1 Advogado inscrito na OAB/BA sob o número 34.950. Especialista em Direito da Propriedade Intelectual pela PUC/RJ, Mestre em Cultura e Sociedade pela UFBA e Doutorando em Cultura e Sociedade na UFBA. Contato: eduardo.ferreira.gomes@hotmail.com
}

2 "A proteção da propriedade intelectual nasce como uma forma de premiar o espírito humano produtivo, e, em contrapartida, exige-se a divulgação de tais tecnologias - antes secretas - para, ao fim do privilégio, todos poderem dele gozar." in BARBOSA, Pedro Marcos Nunes. A usucapião nos privilégios de invenção: a apropriabilidade originária pelo uso reiterado. Dissertação (mestrado). Rio de Janeiro: Universidade do Estado do Rio de Janeiro, Faculdade de Direito, 2011, p.31.

3 A Organização Mundial da Propriedade Intelectual (em inglês, World Intellectual Property Organization - WIPO), foi criada em 14 de julho de 1967, pela Convenção de Estocolmo, como uma das dezesseis instituições no âmbito do Sistema das Nações Unidas, para administrar acordos e tratados multilaterais como a Convenção de Paris para a Proteção da Propriedade Industrial, de 1883, e a Convenção de Berna, de 1886, esta, abrangendo a proteção das obras literárias e artísticas. O Brasil aderiu à Convenção de Estocolmo em 1975 (Decreto n. $\left.{ }^{\circ} 75.541 / 75\right)$, sendo um dos 135 atuais Estados-membros. 
4 "O Sistema de Proteção da Propriedade Intelectual foi criado a partir das Convenções Internacionais de Paris para a Proteção da Propriedade Industrial, para a Proteção das Patentes de Invenção, Marcas, Modelos de Utilidade, de março de 1883 e a Convenção de Berna para a Proteção das Obras Literárias e Artísticas, de 9 de setembro de 1986. Ambas foram sendo aperfeiçoadas periodicamente a cada avanço tecnológico sofrendo cada qual atualizações, com especial atenção na revisão de Estocolmo (1967), quando foi criada a Organização Mundial de Propriedade Intelectual (OMPI).

Mais recentemente, na Rodada Uruguai do GATT, em 1994, as discussões sobre a tutela da propriedade intelectual tiveram grande relevo e impacto, cujo resultado foi o estabelecimento de regras sobre aspectos do direito de propriedade intelectual relacionados ao comércio e, posteriormente, anexados ao Tratado Constitutivo da Organização Mundial do Comércio (OMC), também criada naquele ano.

A tutela à propriedade intelectual se opera no âmbito do Direito Interno e do Direito Internacional, visando à proteção do criador. Num primeiro momento, o inventor estaria protegido de acordo com as leis de seu Estado. Num segundo, pelas normativas internacionais ou comunitárias que regulavam a propriedade intelectual."In WACHOWICZ, Marcos. Direito Autoral. Disponível em http://www.direitoautoral.ufsc.br/gedai/ download/1/, Acesso em 13/11/12.

5 "É verdade que o direito autoral nos é hoje imposto por convenções internacionais. Mas o fundamento em convenções internacionais é ainda um fundamento positivo, ao sabor dos interesses internacionais hegemônicos. Neste domínio, são hoje inevitáveis as questões que possam resultar do ADPIC / TRIPS de 1994, Acordo anexo ao Tratado que criou a Organização Mundial do Comércio. Incorporou as disposições substantivas da Convenção de Bernae desenvolveu-as, pelo prisma do comércio internacional. Passou com isto a ser a entidade determinante a nível global sobre o Direito Intelectual Internacional, dados os poderes de imediata vinculação de que desfruta. Os Estados não têm opção real, porque a alternativa é ficarem privados de participar do comércio internacional, o que hoje não é hoje sequer concebível." In ASCENSÃO, José de Oliveira. Direito Autoral. Rio de Janeiro: Renovar, 1997. p. 17.

6 Trata-se de uma noção de conceito como é utilizado nas ciências sociais, pois a palavra cultura é aplicada a inúmeras realidades, como cultura da terra, cultura física, cultura microbiana, cultura do solo, cultura de animais etc.

7 "Termo introduzido no final do século XIX por antropólogos anglo-saxões para designar os fenômenos de contato direto e prolongado entre duas culturas diferentes que levam a transformações em qualquer delas ou em ambas.

$\mathrm{Na}$ atualidade, o termo é usado, por vezes, para indicar a resultante de uma pluralidade de formas de in- tercâmbio entre os diversos modos culturais - cultura erudita, popular, cultura empresarial etc. - que geram processos de adaptação, assimilação, empréstimo, sincretismo, interpretação, resistência (reação contra-aculturativa), ou rejeição de componentes de um sistema identitário por um outro sistema identitário. Modos culturais compósitos, como óperas montadas e, estádios de futebol, espetáculos de dança moderna apoiados em manifestações de origem popular como o jazz, exemplificam processos de aculturação ou de culturas híbridas."In COELHO, Teixeira. Dicionário crítico de política cultural: cultura e imaginário. 2.ed. São Paulo: lluminuras, 2012, p. 46.

8 De acordo com o art. $5^{\circ}$, IX, da LDA, fonograma é "toda fixação de sons de uma execução ou interpretação ou de outros sons, ou de uma representação de sons que não seja uma fixação incluída em uma obra audiovisual.".

'Fonograma é a fixação de uma obra em suporte material. Para que nos entendam de maneira mais simples é obra gravada', esclareceu o gerente de documentação da ABRAMUS Gustavo Vianna. Logo que a obra é gravada, os titulares que participaram dessa gravação: intérpretes, músicos, acompanhantes e produtores fonográficos (que podem ser os próprios intérpretes), podem receber direitos autorais. Ou seja, passam a ganhar cada vez que a música é reproduzida de maneira pública. Para isso, o fonograma tem de estar cadastrado junto ao ECAD, o que se faz por meio do International Standard RecordinCode (ISRC). Ele é o código que identifica as gravações sonoras e audiovisuais e determina o quanto cada artista receberá percentualmente. No Brasil, a obrigatoriedade da menção desse código no suporte material que contenha o fonograma está regulamentado pelo do Decreto $n^{\circ}$. 4.533, de 19 de dezembro de 2002. 'Quando o intérprete está vinculado a uma gravadora, esta é a responsável pela geração dos códigos ou até o próprio intérprete, no caso das produções independentes', explica Viana. O ECAD é o único órgão responsável por arrecadar os direitos de execução pública e fazer a distribuição aos titulares por meio de suas sociedades." In http://www. abramus.org.br/musica/343/cadastro-de-fonogramas/ Acesso em 20/11/13. 